\title{
Article
}

\section{Perspectives of people with late age- related macular degeneration on mental health and mental wellbeing programmes: a qualitative study}

Dillon, Lisa, Gandhi, Sarthak, Tang, Diana, Liew, Gerald, Hackett, Maree, Craig, Ashley, Mitchell, Paul, Keay, Lisa and Gopinath, Bamini

Available at http://clok.uclan.ac.uk/36487/

Dillon, Lisa, Gandhi, Sarthak, Tang, Diana, Liew, Gerald, Hackett, Maree ORCID: 0000-0003-1211-9087, Craig, Ashley, Mitchell, Paul, Keay, Lisa and Gopinath, Bamini (2021) Perspectives of people with late age-related macular degeneration on mental health and mental wellbeing programmes: a qualitative study. Ophthalmic and Physiological Optics, 41 (2). pp. 255-265. ISSN 0275-5408

It is advisable to refer to the publisher's version if you intend to cite from the work. http://dx.doi.org/10.1111/opo.12779

For more information about UCLan's research in this area go to http://www.uclan.ac.uk/researchgroups/ and search for <name of research Group>.

For information about Research generally at UCLan please go to http://www.uclan.ac.uk/research/

All outputs in CLoK are protected by Intellectual Property Rights law, including Copyright law. Copyright, IPR and Moral Rights for the works on this site are retained by the individual authors and/or other copyright owners. Terms and conditions for use of this material are defined in the policies page. 

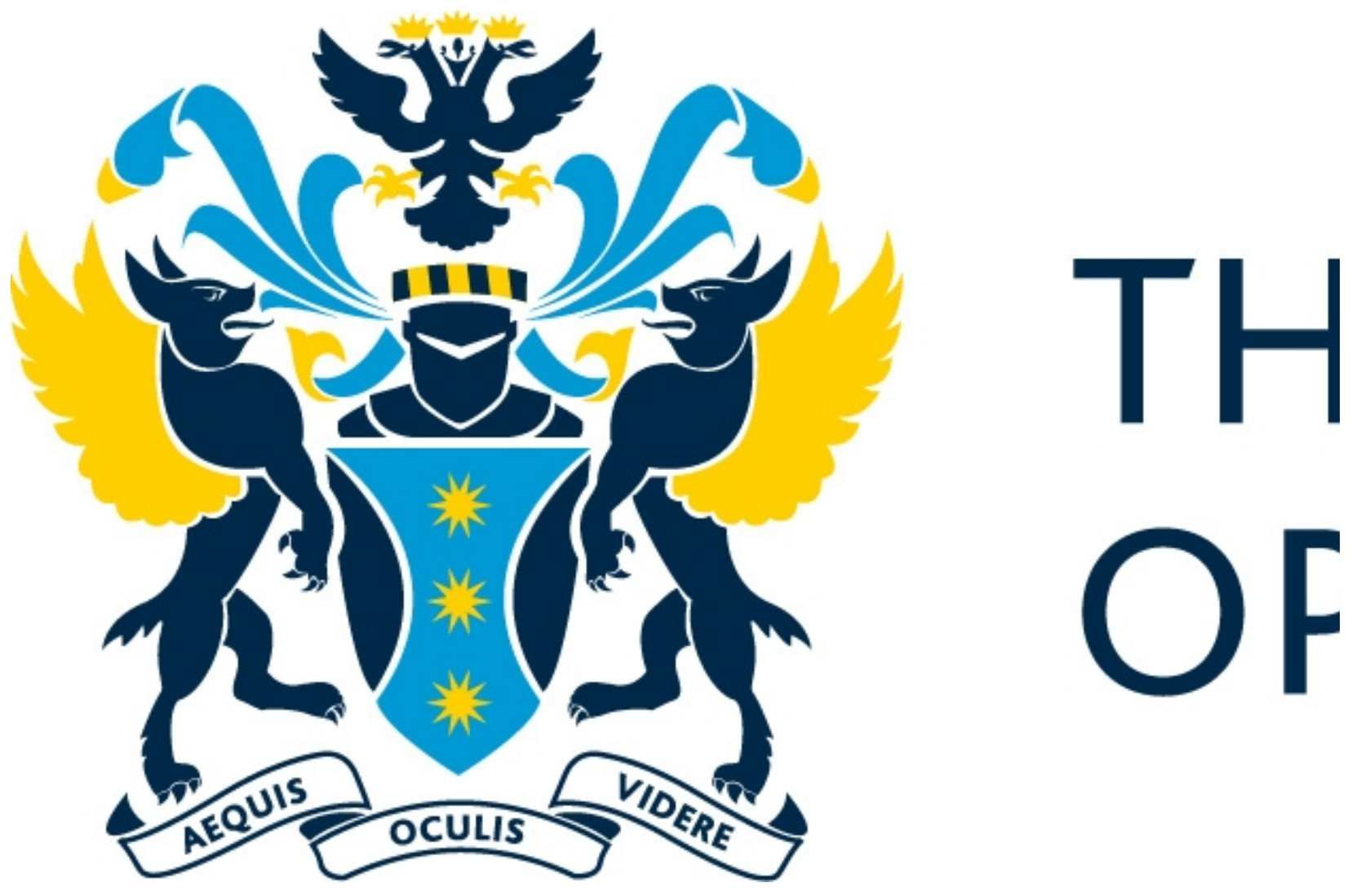

\section{Perspectives of people with late age-related macular degeneration on mental health and mental wellbeing programs: a qualitative study}

\begin{tabular}{|c|c|}
\hline Journal: & Ophthalmic and Physiological Optics \\
\hline Manuscript ID & OPO-OA-3032.R2 \\
\hline Manuscript Type: & Original Article \\
\hline $\begin{array}{r}\text { Date Submitted by the } \\
\text { Author: }\end{array}$ & 23-Nov-2020 \\
\hline Complete List of Authors: & $\begin{array}{l}\text { Dillon, Lisa; University of New South Wales, School of Optometry and } \\
\text { Vision Science; The George Institute for Global Health, Injury Division } \\
\text { Gandhi, Sarthak; Monash University, Faculty of Medicine, Nursing and } \\
\text { Health Sciences; The University of Sydney Faculty of Medicine and } \\
\text { Health } \\
\text { Tang, Diana; The University of Sydney, Centre for Vision Research, } \\
\text { Department of Ophthalmology and The Westmead Institute for Medical } \\
\text { Research } \\
\text { Liew, Gerald; The University of Sydney, Centre for Vision Research, } \\
\text { Department of Ophthalmology and The Westmead Institute for Medical } \\
\text { Research } \\
\text { Hackett, Maree; The George Institute for Global Health; University of } \\
\text { Central Lancashire, Faculty of Health and Wellbeing } \\
\text { Craig, Ashley; The University of Sydney, John Walsh Centre for }\end{array}$ \\
\hline
\end{tabular}


Rehabilitation Research, Northern Clinical School, Faculty of Medicine and Health

Mitchell, Paul; The University of Sydney, Centre for Vision Research, Department of Ophthalmology and The Westmead Institute for Medical Research

Keay, Lisa; University of New South Wales, School of Optometry and Vision Science; The George Institute for Global Health, Injury Gopinath, Bamini; The University of Sydney, Centre for Vision Research, Department of Ophthalmology and The Westmead Institute for Medical Research

Keywords:

Age-Related Macular Degeneration, mental health, qualitative study, wellbeing programs, depression

\section{SCHOLARONE" Manuscripts}


Table 1 Demographic characteristics of participants $(n=29)$

\begin{tabular}{|c|c|c|c|c|c|c|}
\hline $\begin{array}{l}\text { Study } \\
\text { ID }\end{array}$ & $\begin{array}{l}\text { Age } \\
\text { (years) }\end{array}$ & Sex & AMD type & $\begin{array}{l}\text { Years } \\
\text { since any } \\
\text { AMD } \\
\text { diagnosis }\end{array}$ & $\begin{array}{l}\text { Visual } \\
\text { Acuity }\end{array}$ & $\begin{array}{l}\text { History of other eye } \\
\text { conditions }\end{array}$ \\
\hline 001 & 83 & Male & $\begin{array}{l}\text { RE: late } \\
\text { (geographic } \\
\text { atrophy and } \\
\text { neovascular) } \\
\text { LE: late } \\
\text { (neovascular) }\end{array}$ & $\begin{array}{l}\mathrm{RE}: 3.5 \\
\mathrm{LE}: 4.5\end{array}$ & $\begin{array}{l}\text { RE: } 6 / 60-3 \\
\text { LE: } 6 / 36+2\end{array}$ & $\begin{array}{l}\text { Cataract in both eyes; } \\
\text { penetrating } \\
\text { keratoplasty in RE } \\
\text { requiring corneal } \\
\text { graft }\end{array}$ \\
\hline 002 & 79 & Male & $\begin{array}{l}\text { RE: late } \\
\text { (neovascular) } \\
\text { LE: late } \\
\text { (neovascular) }\end{array}$ & $\begin{array}{l}\text { RE: } 16 \\
\text { LE: } 12\end{array}$ & $\begin{array}{l}\text { RE: } 6 / 60-3 \\
\text { LE: } 6 / 60-1\end{array}$ & Cataract in both eyes \\
\hline 003 & 82 & Male & $\begin{array}{l}\text { RE: late } \\
\text { (neovascular) } \\
\text { LE: - }\end{array}$ & $\begin{array}{l}\text { RE: } 8.5 \\
\text { LE: - }\end{array}$ & $\begin{array}{l}\text { RE: } 2 / 60 \\
\text { LE: } 6 / 24+2\end{array}$ & $\begin{array}{l}\text { Diabetic retinopathy } \\
\text { and cataract in both } \\
\text { eyes }\end{array}$ \\
\hline 004 & 74 & Female & $\begin{array}{l}\text { RE: late } \\
\text { (neovascular) } \\
\text { LE: - }\end{array}$ & $\begin{array}{l}\text { RE: } 6 \\
\text { LE: - }\end{array}$ & $\begin{array}{l}\text { RE: } 6 / 7.5 \\
\text { LE: Hand } \\
\text { movements }\end{array}$ & $\begin{array}{l}\mathrm{RE} \text { is the only eye } \\
\text { Cataract in RE }\end{array}$ \\
\hline 005 & 83 & Male & $\begin{array}{l}\text { RE: no AMD } \\
\text { LE: late } \\
\text { (neovascular) }\end{array}$ & $\begin{array}{l}\text { RE: - } \\
\text { LE: } 1\end{array}$ & $\begin{array}{l}\text { RE: } 6 / 12 \\
\text { LE: } 2 / 60\end{array}$ & $\begin{array}{l}\text { Glaucoma and } \\
\text { cataract in both eyes }\end{array}$ \\
\hline 006 & 81 & Female & $\begin{array}{l}\text { RE: no AMD } \\
\text { LE: late } \\
\text { (neovascular) }\end{array}$ & $\begin{array}{l}\mathrm{RE}:- \\
\mathrm{LE}: 0.5\end{array}$ & $\begin{array}{l}\text { RE: } \\
6 / 48+2 \\
\text { LE: } 6 / 7.5-2 \\
\end{array}$ & Cataract in both eyes \\
\hline 007 & 76 & Male & $\begin{array}{l}\text { RE: no AMD } \\
\text { LE: late } \\
\text { (neovascular) }\end{array}$ & $\begin{array}{l}\text { RE: - } \\
\text { LE: } 1\end{array}$ & $\begin{array}{l}\text { RE: } 6 / 15-1 \\
\text { LE: } 6 / 18+1\end{array}$ & $\begin{array}{l}\text { Glaucoma and } \\
\text { cataract in both eyes }\end{array}$ \\
\hline 008 & 83 & Female & $\begin{array}{l}\text { RE: late } \\
\text { (neovascular) } \\
\text { LE: late } \\
\text { (neovascular) }\end{array}$ & $\begin{array}{l}\mathrm{RE}: 4.5 \\
\mathrm{LE}: 4\end{array}$ & $\begin{array}{l}\text { RE: } 6 / 36-2 \\
\text { LE: } 6 / 48+2\end{array}$ & Cataract in both eyes \\
\hline 009 & 81 & Female & $\begin{array}{l}\text { RE: late } \\
\text { (neovascular) } \\
\text { LE: late } \\
\text { (geographic } \\
\text { atrophy) } \\
\end{array}$ & $\begin{array}{l}\mathrm{RE}: 10 \\
\mathrm{LE}: 1.5\end{array}$ & $\begin{array}{l}\text { RE: } 6 / 60-4 \\
\text { LE: } 6 / 15-1\end{array}$ & Cataract in both eyes \\
\hline 010 & 75 & Female & $\begin{array}{l}\text { RE: late } \\
\text { (neovascular) } \\
\text { LE: no AMD }\end{array}$ & RE: 2 & $\begin{array}{l}\text { RE: } 6 / 60-2 \\
\text { LE: } 6 / 9-2\end{array}$ & Cataract in both eyes \\
\hline 011 & 74 & Female & $\begin{array}{l}\text { RE: late } \\
\text { (neovascular) } \\
\text { LE: early } \\
\end{array}$ & $\begin{array}{l}\text { RE: } 1 \\
\text { LE: } 1\end{array}$ & $\begin{array}{l}\text { RE: } 6 / 9+2 \\
\text { LE: } 6 / 7.5-1\end{array}$ & $\begin{array}{l}\text { Cataract in both eyes; } \\
\text { detached retina in RE }\end{array}$ \\
\hline 012 & 81 & Female & $\begin{array}{l}\text { RE: late } \\
\text { (geographic }\end{array}$ & $\begin{array}{l}\text { RE: } 5 \\
\text { LE:5 }\end{array}$ & $\begin{array}{l}\text { RE: } 1 / 60 \\
\text { LE: } 6 / 60-3\end{array}$ & Cataract in both eyes \\
\hline
\end{tabular}




\begin{tabular}{|c|c|c|c|c|c|c|}
\hline & & & $\begin{array}{l}\text { atrophy and } \\
\text { neovascular) } \\
\text { LE: late } \\
\text { (geographic } \\
\text { atrophy) }\end{array}$ & & & \\
\hline 013 & 74 & Male & $\begin{array}{l}\text { RE: early } \\
\text { LE: late } \\
\text { (neovascular) }\end{array}$ & $\begin{array}{l}\text { RE: } 2 \\
\text { LE: } 2\end{array}$ & $\begin{array}{l}\text { RE: } \\
6 / 9.5+2 \\
\text { LE: } 6 / 48-3 \\
\end{array}$ & - \\
\hline 014 & 56 & Male & $\begin{array}{l}\text { RE: no AMD } \\
\text { LE: late } \\
\text { (neovascular) }\end{array}$ & $\begin{array}{l}\text { RE: - } \\
\text { LE: } 1\end{array}$ & $\begin{array}{l}\text { RE: } 6 / 7.5 \\
\text { LE: } 6 / 24+2\end{array}$ & $\begin{array}{l}\text { Central serous } \\
\text { retinopathy and } \\
\text { cataract in both eyes }\end{array}$ \\
\hline 015 & 82 & Female & $\begin{array}{l}\text { RE: late } \\
\text { (neovascular) } \\
\text { LE: late } \\
\text { (neovascular) }\end{array}$ & $\begin{array}{l}\text { RE: } 6.5 \\
\text { LE: } 2\end{array}$ & $\begin{array}{l}\text { RE: } 6 / 9+2 \\
\text { LE: } 6 / 12-1\end{array}$ & Cataract in both eyes \\
\hline 016 & 78 & Female & $\begin{array}{l}\text { RE: late } \\
\text { (neovascular) } \\
\text { LE: late } \\
\text { (neovascular) }\end{array}$ & $\begin{array}{l}\text { RE: } 2 \\
\text { LE: } 2\end{array}$ & $\begin{array}{l}\text { RE: } 6 / 9-1 \\
\text { LE: } 6 / 60-4\end{array}$ & Cataract in both eyes \\
\hline 017 & 79 & Male & $\begin{array}{l}\text { RE: late } \\
\text { (neovascular) } \\
\text { LE: early }\end{array}$ & $\begin{array}{l}\mathrm{RE}: 4.5 \\
\mathrm{LE}: 1.5\end{array}$ & $\begin{array}{l}\text { RE: } \\
6 / 24+1 \\
\text { LE: } 6 / 7.5\end{array}$ & Cataract in both eyes \\
\hline 018 & 82 & Male & $\begin{array}{l}\text { RE: late } \\
\text { (neovascular) } \\
\text { LE: late } \\
\text { (neovascular) }\end{array}$ & $\begin{array}{l}\mathrm{RE}: 5.5 \\
\mathrm{LE}: 4.5\end{array}$ & $\begin{array}{l}\text { RE: } 6 / 24 \\
\text { LE: } 2 / 60\end{array}$ & $\begin{array}{l}\text { Glaucoma and } \\
\text { cataract in both eyes; } \\
\text { cystoid macular } \\
\text { oedema in RE }\end{array}$ \\
\hline 019 & 66 & Female & $\begin{array}{l}\text { RE: early } \\
\text { LE: late } \\
\text { (neovascular) }\end{array}$ & $\begin{array}{l}\text { RE: } 2.5 \\
\text { LE: } 2.5\end{array}$ & $\begin{array}{l}\text { RE: } 6 / 18 \\
\text { LE: } 6 / 15\end{array}$ & Cataract in both eyes \\
\hline 020 & 77 & Male & $\begin{array}{l}\text { RE: late } \\
\text { (neovascular) } \\
\text { LE: late } \\
\text { (neovascular) }\end{array}$ & $\begin{array}{l}\text { RE: } 9 \\
\text { LE: } 7\end{array}$ & $\begin{array}{l}\text { RE: } 6 / 12 \\
\text { LE: } 6 / 7.5\end{array}$ & Cataract in both eyes \\
\hline 021 & 87 & Female & $\begin{array}{l}\text { RE: late } \\
\text { (neovascular) } \\
\text { LE: late } \\
\text { (neovascular) }\end{array}$ & $\begin{array}{l}\text { RE: } 2.5 \\
\text { LE: } 2.5\end{array}$ & $\begin{array}{l}\text { RE: } 6 / 60-2 \\
\text { LE: } 6 / 48-1\end{array}$ & Cataract in LE \\
\hline 022 & 82 & Male & $\begin{array}{l}\text { RE: no AMD } \\
\text { LE: late } \\
\text { (neovascular) }\end{array}$ & $\begin{array}{l}\text { RE: - } \\
\text { LE: } 9.5\end{array}$ & $\begin{array}{l}\text { RE: } 6 / 9-1 \\
\text { LE: } 6 / 60-1\end{array}$ & $\begin{array}{l}\text { Polypoidal choroidal } \\
\text { vasculopathy and } \\
\text { cataract in both eyes }\end{array}$ \\
\hline 023 & 78 & Male & $\begin{array}{l}\text { RE: late } \\
\text { (neovascular) } \\
\text { LE: late } \\
\text { (neovascular) }\end{array}$ & $\begin{array}{l}\text { RE: } 4 \\
\text { LE: } 14.5\end{array}$ & $\begin{array}{l}\text { RE: } 6 / 24 \\
\text { LE: } 6 / 60-2\end{array}$ & - \\
\hline 024 & 84 & Female & $\begin{array}{l}\text { RE: late } \\
\text { (neovascular) } \\
\text { LE: late } \\
\text { (neovascular) }\end{array}$ & $\begin{array}{l}\text { RE: } 9 \\
\text { LE: } \\
\text { newly } \\
\text { diagnosed }\end{array}$ & $\begin{array}{l}\text { RE: } \\
6 / 7.5+2 \\
\text { LE: } 6 / 9-1\end{array}$ & Cataract in both eyes \\
\hline
\end{tabular}




\begin{tabular}{|c|c|c|c|c|c|c|}
\hline 025 & 59 & Female & $\begin{array}{l}\text { RE: late } \\
\text { (neovascular) } \\
\text { LE: - }\end{array}$ & $\begin{array}{l}\text { RE: } 3.5 \\
\text { LE: - }\end{array}$ & $\begin{array}{l}\text { RE: } 6 / 12 \\
\text { LE: } 6 / 48\end{array}$ & $\begin{array}{l}\text { Myopic macular } \\
\text { degeneration and } \\
\text { cataract in both eyes }\end{array}$ \\
\hline 026 & 83 & Female & $\begin{array}{l}\text { RE: late } \\
\text { (neovascular) } \\
\text { LE: - }\end{array}$ & $\begin{array}{l}\text { RE: } 2 \\
\text { LE: - }\end{array}$ & $\begin{array}{l}\text { RE: } 6 / 36-1 \\
\text { LE: } 6 / 6\end{array}$ & $\begin{array}{l}\text { Glaucoma in RE and } \\
\text { cataract in both eyes }\end{array}$ \\
\hline 027 & 85 & Female & $\begin{array}{l}\text { RE: late } \\
\text { (geographic } \\
\text { atrophy and } \\
\text { neovascular) } \\
\text { LE: late } \\
\text { (geographic } \\
\text { atrophy) }\end{array}$ & $\begin{array}{l}\text { RE: } 6 \\
\text { LE: } 6\end{array}$ & $\begin{array}{l}\text { RE: } 6 / 30-2 \\
\text { LE: } 6 / 60-3\end{array}$ & Cataract in both eyes \\
\hline 028 & 77 & Female & $\begin{array}{l}\text { RE: early } \\
\text { LE: early }\end{array}$ & $\begin{array}{l}\text { RE: } 6 \\
\text { LE: } 6\end{array}$ & $\begin{array}{l}\text { RE: } \\
6 / 12+1 \\
\text { LE: } 6 / 48\end{array}$ & $\begin{array}{l}\text { Glaucoma and } \\
\text { cataract in both eyes }\end{array}$ \\
\hline 029 & 72 & Male & $\begin{array}{l}\text { RE: late } \\
\text { (geographic } \\
\text { atrophy) } \\
\text { LE: late } \\
\text { (geographic } \\
\text { atrophy) }\end{array}$ & $\begin{array}{l}\text { RE: } 7 \\
\text { LE: } 7\end{array}$ & $\begin{array}{l}\text { RE: } \\
6 / 15+2 \\
\text { LE: } 6 / 60\end{array}$ & $\begin{array}{l}\text { Diabetic retinopathy } \\
\text { in right eye }\end{array}$ \\
\hline
\end{tabular}




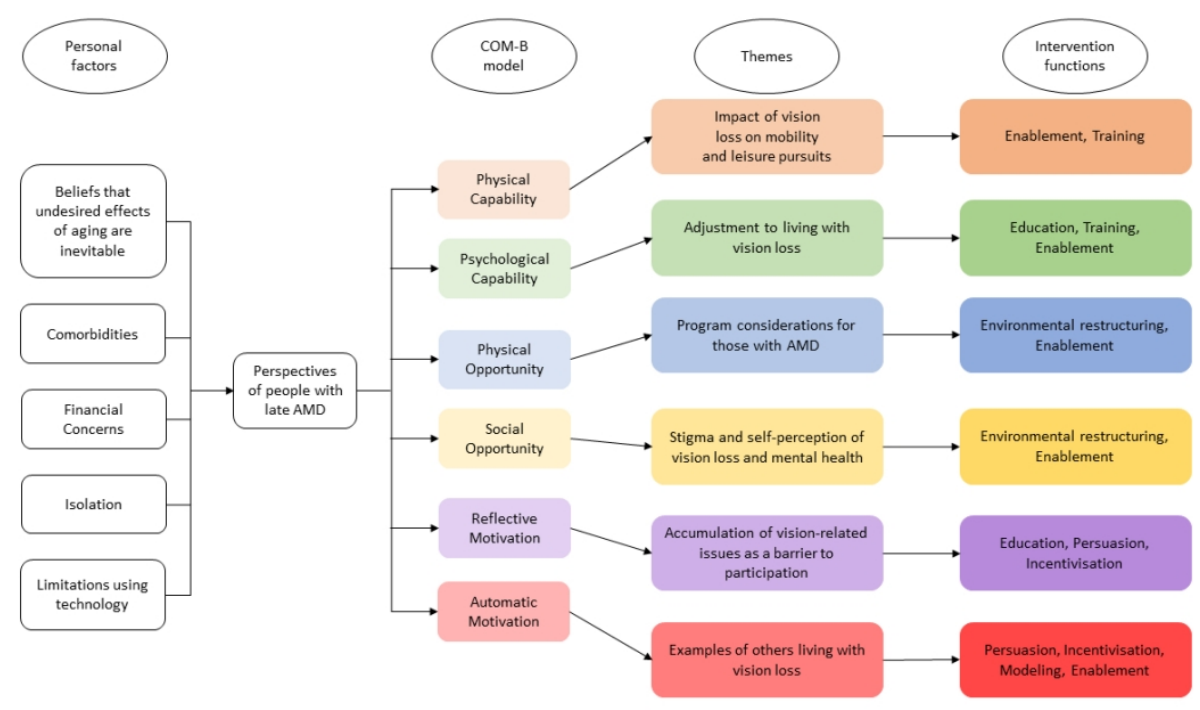

Figure 1. The impact of vision loss on mental health and mental wellbeing programs, from the perspectives of people primarily with late AMD, based on the Capability, Opportunity, Motivation and Behaviour (COM-B) model (inner wheel) and intervention functions (outer wheel) of the behaviour change wheel.23 Personal factors which may have influenced these perspectives are also displayed.

$338 \times 190 \mathrm{~mm}(96 \times 96 \mathrm{DPI})$ 
Mental health and age-related macular degeneration

Title:

Perspectives of people with late age-related macular degeneration on mental health and mental wellbeing programmes: a qualitative study

Running head: Mental health and age-related macular degeneration

\section{Authors:}

Lisa Dillon ${ }^{\mathrm{a} b *} \uparrow$, Sarthak Gandhic $\mathrm{d} \uparrow$, Diana Tang ${ }^{\mathrm{e}}$, Gerald Liew, Maree Hackett ${ }^{\mathrm{b}}$, Ashley Craig ${ }^{\mathrm{g}}$, Paul Mitchell, Lisa Keay ${ }^{\mathrm{ab}}$ and Bamini Gopinath ${ }^{\mathrm{e}}$

a School of Optometry and Vision Science, UNSW Sydney, Kensington, Australia

${ }^{\mathrm{b}}$ The George Institute for Global Health, Faculty of Medicine, UNSW Sydney, Newtown, Australia;

${ }^{c}$ Faculty of Medicine, Nursing and Health Sciences, Monash University, Melbourne, Australia;

${ }^{\mathrm{d}}$ Faculty of Medicine and Health, The University of Sydney, Sydney, Australia;

${ }^{\mathrm{e}}$ Centre for Vision Research, Department of Ophthalmology and The Westmead Institute for Medical Research, The University of Sydney, Sydney, Australia;

${ }^{\mathrm{f}}$ Faculty of Health and Wellbeing, University of Central Lancashire, Preston, United Kingdom;

g John Walsh Centre for Rehabilitation Research, Northern Clinical School, Faculty of Medicine and Health, The University of Sydney, St. Leonards, Australia

*Corresponding author: lisa.dillon1@unsw.edu.au

$\dagger$ Lisa Dillon and Sarthak Gandhi contributed equally to this paper as joint-first authors

Keywords: $\quad$ mental health; macular degeneration; qualitative study; wellbeing programmes; depression

\section{Author contributions:}


Mental health and age-related macular degeneration

\begin{abstract}
Purpose: People with age-related macular degeneration (AMD) experience high rates of depression, but rarely engage in or have access to tailored mental wellbeing programmes. This qualitative study investigated the perspectives of those primarily with late AMD on mental health and mental wellbeing programmes.
\end{abstract}

Methods: Twenty-eight people with late AMD in at least one eye, and one person with early AMD in both eyes, aged 56-87 years (mean age 78 years) attending a private eye clinic between December 2019 and January 2020 in Sydney, New South Wales, Australia, participated. Individual semi-structured interviews were conducted and analysed deductively using content analysis, following the individual level factors for health promotion interventions in the behaviour change wheel: Capability (Physical \& Psychological), Opportunity (Physical \& Social), and Motivation (Reflective \& Automatic).

Results: Six major themes were identified: Capability: (1) Impact of vision loss on mobility and leisure pursuits; (2) Adjustment to living with vision loss; Opportunity: (3) Program considerations for those with AMD; (4) Stigma and self-perception of vision loss and mental health; Motivation: (5) Accumulation of vision-related issues as a barrier to participation; (6) Examples of others living with vision loss. General personal factors relevant to delivery of a program in this age group were also identified: Comorbidities; Limitations using technology; Isolation; Financial concerns; and Beliefs that undesired effects of aging are inevitable.

Conclusions: Complex individual, environmental and social factors influence the perspectives of people with late AMD on mental health, and potential participation in mental wellbeing programmes. These factors should be considered when developing and implementing mental wellbeing programmes to improve the emotional and functional rehabilitation outcomes for people with AMD. 
Mental health and age-related macular degeneration

\section{INTRODUCTION}

Age-related macular degeneration (AMD) is a progressive, chronic disease impacting central vision, and is a major cause of low vision and blindness in older age. ${ }^{1,2}$ Globally, 196 million people were affected by AMD in 2020, with this number projected to increase to 288 million by $2040 .{ }^{3}$ The two main stages of AMD are early and late, with vision loss characteristic of late AMD. Late AMD is further subdivided into neovascular and geographic atrophy AMD, with the classification based upon the presence or absence of choroidal neovascularisation (abnormal blood vessels), respectively. ${ }^{4}$ The neovascular form affects around 10-15\% of people with AMD and accounts for approximately $90 \%$ of cases of severe vision loss due to AMD. ${ }^{5}$ Neovascular AMD can be managed with a range of antiangiogenic treatments but there is often persistent vision impairment. ${ }^{6}$

Despite treatment, AMD can have a profoundly negative effect on the quality of life. The greatest effects have been reported as a result of restrictions in reading, leisure activities and shopping. ${ }^{7}$ Irrespective of the degree of vision loss, there is also a high level of emotional distress, such as worry and frustration about vision loss, with many expressing concern about their eyesight getting worse and their ability to cope with everyday life. ${ }^{7}$ Notably, ratings of quality of life and emotional distress have been shown to be significantly worse among people with AMD, compared with similarly aged community dwelling adults with chronic illness. $^{8}$

The prevalence of depression among patients with AMD is $32.5 \%(n=151,>60$ years old $){ }^{9}$ i.e., twice the frequency identified in studies of community-dwelling older people. ${ }^{10,11}$ This is very concerning given that $33 \%(n=51)$ of those with depression also have greater levels of vision-specific and general physical disability, and slightly worse visual acuity than nondepressed participants. ${ }^{12}$ This highlights the close relationship between AMD and mental health disorders, with both cumulatively leading to substantial functional impairment.

Although mental health disorders are treatable, approximately $60 \%$ of a nationally representative sample of Australians aged 55 to 64 years meeting the criteria for a mental disorder did not make use of mental health services. ${ }^{13}$ Similar data are seen in American older adults, where approximately $70 \%(n=348,>55$ years old) with mood and anxiety disorders did not use mental health services. ${ }^{14}$ This highlights the need for and access to programmes that focus on mental wellbeing for older people, particularly those with AMD who are at risk of the cumulative impact of vision loss and mental health issues. Shared- 
Mental health and age-related macular degeneration

decision making has been suggested to improve adherence to mental health services and patient-centred care. ${ }^{15}$ This serves to heighten trust and acceptance of potential evidencebased programmes ensuring adherence and mental health issues experienced by this population can be appropriately targeted with effective interventions.

Low-vision rehabilitation services have been shown to improve vision-specific quality of life; however, these services were shown to have little impact on depressive symptoms. ${ }^{16} \mathrm{~A}$ lowvision self-management programme has also been shown to have very little benefit on quality of life in older adults accessing low vision services. ${ }^{17}$ However, psychosocial interventions ${ }^{18}$ and psychological therapies ${ }^{19}$ have been shown to have a positive impact on depression in adults aged 18 years or older with low vision. These psychological therapies have been mainly developed and tested in people with AMD, and to a lesser extent in those with glaucoma, Stargardt disease, or in general low vision or unspecified populations. ${ }^{19} \mathrm{We}$ aimed to investigate the perspectives of people with AMD on mental wellbeing programmes in a novel qualitative study in order to involve them meaningfully in planning, developing and implementing a psychological programme targeting depression and anxiety. Given the high prevalence of AMD and the debilitating nature of the condition itself and associated issues such as elevated anxiety and depression, the development of interventions targeted to this population is integral to improving their quality of life and functional independence.

\section{METHODS}

This study is reported in line with the Consolidated Criteria for Reporting Qualitative Research (COREQ) statement (Supplementary File 1). ${ }^{20}$

\section{Design and setting}

A qualitative study investigated the perspectives of people primarily with late AMD and the factors that influenced their participation in mental wellbeing programmes. Semi-structured interviews were used due to their flexibility and ability to collect rich narrative data. ${ }^{21}$ This study was conducted at the Sydney West Retina Clinic (private eye clinic), located in Westmead, Sydney, Australia. Patients of this high-volume clinic are not required to pay any out of pocket costs if eligible for Medicare rebates.

\section{Study participants}

People with AMD were recruited from the clinic using convenience sampling, and recruitment stopped when data was considered saturated. Data saturation was assessed at regular weekly project meetings by researchers (LD, SG), and considered achieved when 
Mental health and age-related macular degeneration

additional data did not lead to the development of new codes. ${ }^{22}$ People diagnosed with AMD were approached by researchers (DT, SG) during their visit to the clinic, and invited to participate. The inclusion criteria were: (1) diagnosed with AMD (both early and late) and (2) aged 50 years or older. Interviewers explained the purpose of the study and gained verbal informed consent before participation, ensuring involvement was voluntary.

\section{Data collection}

One-to-one, face-to-face, semi-structured interviews were conducted with consenting participants who met the inclusion criteria. Interviews were conducted by an undergraduate medical student (SG), who received initial and ongoing training from an experienced Faculty of Medicine and Health PhD student (DT), and two senior qualitative researchers (BG, LD). A semi-structured guide was developed using the behaviour change wheel framework. ${ }^{23}$ The framework emphasises the relationships between individual behaviour change and intervention design. This was appropriate to understanding the perspectives of people with AMD about mental health and consequent design of a mental health programme.

The interviews were performed in a quiet room at the clinic, but could be interrupted when a participant was called on by a clinician for treatment or consultation, and then resumed when possible. The questions were focused on exploring the experience of participants and what support or programmes they would like to engage with, should these be available. The openended question style served to facilitate more responses from participants, and allowed them to expand on and discuss their thoughts. ${ }^{21}$ The semi-structured interview guide is included in Supplementary File 2. Some examples of specific questions included; "Can you tell me a bit more about your macular degeneration?", "What is your understanding regarding support programmes for AMD patients to help cope with the condition?", "Are you aware of any support services out there in general?", "What are some concerns you have regarding your mental health?" and "What do you think should be involved in a mental health programme developed for people with vision impairment?".

Each interview was audio recorded, transcribed verbatim and analysed using word processing software. Transcripts were not returned to participants for comment and/or correction, nor were repeat interviews conducted. Participant demographic information was collected from the medical record at the clinic following completion of each interview. This included age (years), sex (male/female), AMD type (late/early) in each eye, time since AMD diagnoses 
Mental health and age-related macular degeneration

(years), visual acuity in each eye, and history of other eye conditions. Some participants were initially seen or treated at another eye clinic, and consequently not all data were available.

\section{Data analysis}

The qualitative data were analysed using the framework from the behaviour change wheel. ${ }^{23}$ Specifically, data were deductively coded using content analysis, ${ }^{24}$ under the headings of the sources of behaviour (Capability, Opportunity, Motivation and Behaviour (COM-B) model, inner wheel), and the intervention functions (middle wheel). ${ }^{23}$ Due to broad application of the behaviour change wheel as a framework, it was not expected that all sources of behaviour or intervention functions would be found to be relevant. Only data that were specifically related to the impact of AMD on the psychological functioning of participants, and perspectives related to the design of a potential programme, were analysed. Personal factors, which may have not been a direct result of vision loss but would likely influence perceptions and participation in a programme, were also documented. We took an iterative approach to data analysis, ${ }^{25}$ whereby data were revisited, coded, and themes discussed many times to ensure analytic reflexivity. Transcripts were coded separately by two researchers (SG, LD), who met weekly to reflect on coding and theme development after each set of 10 transcripts were completely read and coded. Initial themes were agreed upon, along with their illustrative quotes, and presented at two meetings with a wider group (BG, LK, DT, SG, LD) for critique and finalisation.

\section{Patient and public involvement}

No participants or members of the public were involved in the design, recruitment or conduct of the study. All participants were informed via email or telephone call about the publication of the results.

\section{Ethics approval}

Ethics approval was granted by the University of New South Wales Human Research Ethics Committee (HC190356).

\section{RESULTS}

\section{Participant characteristics}

Twenty-nine participants with AMD were recruited from December 2019 to January 2020. A further participant had been recruited, but their vision impairment did not include a diagnosis of AMD, and they were subsequently excluded. Average age was 78 (standard deviation $=7$, 
Mental health and age-related macular degeneration

range $=56$ to 87$)$ years old. Participants were mostly female $(16 / 29,55 \%)$, and had late stage $\operatorname{AMD}(28 / 29,97 \%)$ in at least one eye (Table 1).

Interviews lasted an average of 17 minutes (range $=4$ to 50 minutes) and varied in length depending on the depth of answers.

\section{Themes}

Six major themes were identified which corresponded with all elements of the Capability, Opportunity, Motivation and Behaviour (COM-B) model, and seven of the nine intervention functions of the behaviour change wheel. ${ }^{23}$ The themes and their relationship to the behaviour change wheel are summarised in Figure 1, and quotes that are more illustrative are presented in Supplementary File 3.

\section{Physical Capability (Training, Enablement)}

Theme 1: Impact of vision loss on mobility and leisure pursuits. Participants reported that vision loss had greatly affected their mobility, and this lack of mobility did not just reduce access to support, but also led to increased isolation from the community, friends and family:

'What am I doing now? Sitting on my bum all bloody day because I can't do anything else. I can't see to go out, I can't catch a bus. I can't catch a train, you know?'

Vision loss reduced their ability to drive, or ability to drive at certain times or for long distances. For some, this changed their perception of themselves as independent, competent individuals:

'I used to do a lot of driving. I've been driving for approximately 65 years. I used to work for a big company. I used to travel interstate all the time...I don't drive anymore. I don't trust myself anymore.'

In particular, all participants mentioned how their vision loss reduced their ability to read:

'I used to be a very, very avid reader of books. I am no longer an avid reader of books.'

Most participants also reported that the vision loss associated with AMD led to a loss of ability to engage in hobby and leisure activities, which was sometimes conceptualised as an inability to participate in all activities: 
Mental health and age-related macular degeneration

'I used to do a lot of crosswords and I used to play a lot of tennis - I can't do anything now.'

However, those who could get access to a low vision aid appeared to be able to continue reading and engage in hobby and leisure activities:

'I'm still able to read but I have a special magnifying glass. It's a good one too. Smaller print, big print - I'm okay.'

\section{Psychological Capability (Education, Training, Enablement)}

Theme 2: Adjustment to living with vision loss. Participants reported varying levels of adjustment to their vision loss. This was mediated by their outlook on diagnosis, acceptance of vision loss and fear of further vision loss:

'I was a pretty secure sort of person. I suppose I don't feel as secure as I used to. I take a risk and go, I won't now because I fear I will fall, or I'll walk into - it's amazing when you can't see properly how much it affects your whole life.'

'And for me, at the moment, I don't consider it a disability. Because I can still see with one good eye. Because I can drive, I can still read, I can use my laptop.'

The impact of vision loss on confidence stopped some participants from getting out in their community with others, despite having the opportunity to do so:

'Your confidence, for one thing. I do get asked out a lot. I've got nice friends from the church and all that but I think no, I won't go cause they've got to watch me and it's only - I'm the one that's stopping myself, not my friends, they are all eager to come and take me out to whatever's on. It's hard when you've been independent and then this happens.'

'It's just amazing that it [vision loss] makes you very fearful.'

\section{Physical Opportunity (Environmental restructuring, Enablement)}

Theme 3: Programme considerations for those with AMD. None of the participants interviewed were aware of mental wellbeing programmes designed for people with vision impairment or AMD:

'I haven't heard of anything as such around our area. I mean there might be stuff, I just haven't...heard of it, no.' 
Mental health and age-related macular degeneration

Participants offered that more appropriate and increased advertising would improve awareness of existing and future support programmes:

'I just think we should advertise the help that we can get more because I don't know what help we've got, but like my son keeps saying, there must be help for people like you. And I'm willing to try things where some might not. I've given up. I mean, I've been like this two year[s]. I've sort of thought I'll just get on and make my own life, yes, so that's what I've done.'

Participants also reported concerns regarding the location, cost and accessibility of existing and proposed programmes:

'But there's just really nothing within an area, easiness to get to [is important]. So, it can be a bit difficult.'

'You also need to think those with visual problems probably don't have the money to come together easily in groups.'

'It [community programme] was no good to me. They would write things on the blackboard and you've got to tell them what it is. Well I couldn't see those things.'

Participants however recognised the benefits of attending programmes on their wellbeing: 'I think it's good for your morale. And I think if you're even people that [sic] are semi-blind or totally blind, they come along and join in with these functions. It's a good feel...one of the old ladies saying that she usually sleeps every afternoon. That particular day, she decided to come to the function, and she enjoyed it so much.'

\section{Social Opportunity (Environmental restructuring, Enablement)}

Theme 4: Stigma and self-perception of vision loss and mental health. Some considered their vision loss or mental health problems were not severe enough to seek services, especially when compared with other people:

'People with vision impairment are very depressed. I mean, to be honest, it's depressing. But as far as I'm concerned, being depressed is something that you have to work your way through or compensate for or whatever.' 
However, many of the participants saw social connection with others, including those with vision impairment, as positive:

'I like it, but a lot of the activities are more of a social event. And I look forward - I like having - I wake up in the morning and if there's an event on today that I really want to go to... and enjoy it...we have our happy hours and function days.'

'And then afterwards we sit down, and we have a chat and that is more important for me that I can talk to someone. More important than anything else.'

\section{Reflective Motivation (Education, Persuasion, Incentivisation)}

Theme 5: Accumulation of vision-related issues as a barrier to participation. Participants were less motivated to engage in a programme due to an accumulation of practical and psychosocial concerns related to their vision loss.

'If you talk to people who are vision impaired, it means they also have to have somebody who's able to take them, bring them home. And it becomes a big effort...[the support] person themselves may not want to give up half a day.'

'Just once you get it, you get it and that's it, sort of thing. See it's all like the girl or the woman, she used to take me out for a walk every so often. Well what's the good of that, I can't see things properly and sometimes I trip over things and, you know, it's just a waste of time sort of thing....and they say I can go out in their bus on outings, but what's the good of that? I can't see properly.

This led to loss of hope or lack of motivation to try anything new or access existing services: 'I had a girl from the council, I think it was from the council, but she tried to help me but there's nothing you can do really.'

\section{Automatic Motivation (Persuasion, Incentivisation, Modelling, Enablement)}

Theme 6: Examples of others living with vision loss. Participants would commonly refer to how others were living or coping with their vision loss, negatively and positively: 
Mental health and age-related macular degeneration

'One of my friends she sort of...let[s] people know that she has low vision and that. And she just went on a cruise with her family recently. She said it was very good because... people were very sort of helpful to her.'

'One woman there...she's about $95 \ldots$ she said that [she] didn't help with the macular at all. She's had them for years. She's still quite good in herself. She's restricted so much with the lack of vision. Well, she always seems to be in good spirits, I always say g'day to her when I see her in the morning. If I see her coming, I actually hold the chair out for her and help her into a chair.'

Participants highlighted the need for good leadership for the support groups, and the importance of having a positive experience the first time they attend:

'That's because of the staff. That's what made a difference. That was the key.'

'You always need leadership. Yeah, and nice leadership, open-style

leadership...if you can find someone important enough or it's - preferably a lady that would be followed by women, because women tend to lead their social circle.'

'You only need to meet one person that you can connect with and you want to go back there.'

'You've got to make sure the first time they attend, it's got to be a good show, otherwise they'll think, that was a waste of time, I'm not coming back... first impressions are always very important.'

\section{Personal factors}

Interviews also revealed complex individual, environmental and social factors influencing participants' perspectives. Although these personal factors, or their impact, were likely exacerbated by vision loss, they are also commonly experienced by older adults more generally. These factors were readily reported by many of the participants and are likely to affect how people primarily with late AMD engage in mental wellbeing programmes. The personal factors are presented in Figure 1, and illustrative quotes are presented in Supplementary File 4. 
Mental health and age-related macular degeneration

\section{DISCUSSION}

This study explored the perspectives of people primarily with late AMD regarding mental health and wellbeing programmes, and considered the individual and interventional factors that influence engagement in such programmes. Of note, most participants were unaware of existing general low vision rehabilitation programmes. Further, none of the participants were aware of programmes specifically aimed at improving the mental wellbeing of those with AMD. Past research has demonstrated lack of knowledge as a major barrier to receipt of mental health services in older adults with vision impairment $(n=871$, mean age $=73$ years $){ }^{26}$ This indicates a worryingly large gap between available services and knowledge given the high frequency of mental health concerns, isolation and loss of functional independence among people with AMD. ${ }^{9}, 12$ Further, older adults with vision impairment who also have depression are more vulnerable to further health decline. ${ }^{27}$ However, participants provided critical insights into the barriers preventing them from engaging in mental wellbeing programmes, if they were available, and offered suggestions as to what elements they would look for in a programme and how these could be implemented. In particular, participants expressed a desire for increased social connection to ameliorate feelings of isolation or loneliness.

Adjustment to living with vision loss was a major theme identified under psychological capability. Our participants had varied outlooks on their vision loss and AMD diagnosis including denial, fear of further decline and acceptance of living with vision loss. We observed better functioning in those with social support, longer-term vision loss, those in receipt of low vision rehabilitation services and those with access to low vision aids. Conversely, we observed worse functioning in those with a fatalistic attitude to the undesirable effects of aging, those fearful of further vision loss and those isolated or not in receipt of low vision rehabilitation services. Adjustment and/or acceptance of vision loss has been shown to increase psychosocial wellbeing and use of services. ${ }^{28}$ However, less than $20 \%$ of older adults with vision impairment engage in rehabilitation services. ${ }^{29}$ Further, those with recent vision loss are more likely to experience higher levels of psychological distress, compared to those with longer-term loss. ${ }^{30}$ Although a lack of adjustment to vision loss may explain why many of our participants were not in receipt of services, our findings suggest that many were completely unaware of existing services. Education may be a mechanism to influence psychological capability, as well as reflective motivation to engage in a programme, indicating people should be provided with education early in their diagnosis of 
Mental health and age-related macular degeneration

AMD. With appropriate training and resources, vision rehabilitation ${ }^{31,32}$ or eye care professionals ${ }^{33}$ may be well placed to deliver this education.

Stigma was a major theme identified under social opportunity, and impacts how those with vision impairment cope with their mental health and vision loss, ${ }^{34}$ and their uptake of psychological support. ${ }^{35}$ Stigma is a major inhibitor of social well-being in older adults with vision impairment, ${ }^{36}$ who often find it difficult to speak with their physician about their concerns. ${ }^{37}$ Vision impairment is considered a challenge to identity, with recognition of vision impairment akin to being 'devalued' or 'sub-human'. Consequently, those with vision impairment were less likely to use mobility aids or engage in social activities in an attempt not to draw attention to their vision impairment. ${ }^{36}$ Similarly a diagnosis of AMD can lead to isolation if individuals chose not to disclose their condition to others. ${ }^{38}$ Programmes aimed at reducing stigma by taking a holistic approach to supporting those adjusting to living with AMD have been recommended. Education, Enablement and Modelling ${ }^{23}$ and associated behaviour change techniques ${ }^{39}$ could be used to design a programme to reduce stigma, and enhance the psychosocial wellbeing of people with AMD.

Our themes of Impact of vision loss on mobility and leisure pursuits and Accumulation of vision-related related issues as a barrier to participation were similar to themes identified in other qualitative studies in people with AMD: functional limitations, adaptation and independence. ${ }^{38}$ Vision loss due to AMD has previously been found to result in limitations of activities of daily living, including reading and driving, ${ }^{38}$ particularly for those with bilateral vision loss. There is vast scope for improved access to and facilitated engagement in low vision rehabilitation services and mental wellbeing programmes, which may lead to a continuation of, or improvement in usual daily activities.

\section{Strengths and limitations}

Semi-structured interviews allowed for tailored discussions and a deeper understanding of the impact of AMD on mental health and perspectives on mental wellbeing programmes. Data saturation was achieved, and we are confident the themes captured the perspectives of this group. However, the study is limited to people who attended one ophthalmology clinic in New South Wales, Australia, the majority of whom have late AMD. Patients of the clinic are not required to pay any out of pocket costs, and see the same healthcare practitioners, reducing the representativeness of our population. Their opinions may be different from people with early AMD, or those who are not receiving treatment or presenting to a different 
Mental health and age-related macular degeneration

clinic. Recruitment and completion of interviews in a quiet room at the clinic was convenient for the participants. However, the flow of some of the interviews were likely interrupted when a participant was called away by the clinician for treatment or consultation during the interview, which may have led to shorter interviews. Additionally, access to definitive information regarding duration and severity of vision loss may have improved our understanding of the impact of AMD and adjustment over time, as well as establishing potential differences in perspectives of those with milder versus more severe vision loss. Finally, none of the participants were aware of mental wellbeing programmes, which may have been a result of the convenience sampling used. Future studies should look to use purposeful sampling of patients with AMD who have previously engaged in a mental wellbeing programme.

\section{Implications for practice and research}

We found that adjustment to vision loss due to AMD, particularly in those with late AMD, is different for every person. Our findings suggest that in order to facilitate adjustment, programmes should aim to reduce the stigma associated with vision loss, account for individual circumstances, and promote engagement in current services. Accessibility is also critical to helping people with AMD participate in appropriate programmes, including regular long-term involvement. Accessibility not only includes accounting for the unique travel concerns faced by those with AMD, but also appropriate marketing, ensuring programmes are engaging by using meaningful speakers and activities and offer opportunities for participants to have some ownership over their content and delivery. Any programmes developed will need to be rigorously tested to ensure efficacy before widespread implementation.

Acknowledgements: This study was supported by the UNSW SOVS Macular Degeneration Research Grant from the Estate of the late Peter Anthony John Vild. We thank the participants that took part in this research.

Disclosure: $\quad$ The authors declare no conflicts of interest and have no proprietary interest in any of the materials mentioned in this article. 
Mental health and age-related macular degeneration

\section{References}

1. Lim LS, Mitchell P, Seddon JM, Holz FG \& Wong TY. Age-related macular degeneration. The Lancet 2012; 379: 1728-1738.

2. Mitchell P, Liew G, Gopinath B \& Wong TY. Age-related macular degeneration. The Lancet 2018; 392: 1147-1159.

3. Wong WL, Su X, Li X et al. Global prevalence of age-related macular degeneration and disease burden projection for 2020 and 2040: A systematic review and metaanalysis. Lancet Glob Health 2014; 2: e106-116.

4. Pennington KL \& DeAngelis MM. Epidemiology of age-related macular degeneration (amd): Associations with cardiovascular disease phenotypes and lipid factors. Eye and Vision 2016; 3: 34

5. Chappelow AV \& Kaiser PK. Neovascular age-related macular degeneration. Drugs 2008; 68: 1029-1036.

6. Hernandez-Zimbron LF, Zamora-Alvarado R, Ochoa-De la Paz L et al. Age-related macular degeneration: New paradigms for treatment and management of amd. Oxid Med Cell Longev 2018; 2018: 8374647.

7. Hassell JB, Lamoureux EL \& Keeffe JE. Impact of age related macular degeneration on quality of life. Br J Ophthalmol 2006; 90: 593-596.

8. Williams RA, Brody BL, Thomas RG, Kaplan RM \& Brown SI. The psychosocial impact of macular degeneration. Archives of Ophthalmology 1998; 116: 514-520.

9. Brody BL, Gamst AC, Williams RA et al. Depression, visual acuity, comorbidity, and disability associated with age-related macular degeneration. Ophthalmology 2001; 108: 1893-1900.

10. Blazer D, Hughes DC \& George LK. The epidemiology of depression in an elderly community population. Gerontologist 1987; 27: 281-287.

11. Newman SC, Sheldon CT \& Bland RC. Prevalence of depression in an elderly community sample: A comparison of gms-agecat and dsm-iv diagnostic criteria. Psychol Med 1998; 28: 1339-1345.

12. Rovner BW, Casten RJ \& Tasman WS. Effect of depression on vision function in agerelated macular degeneration. Archives of Ophthalmology 2002; 120: 1041-1044.

13. Burgess PM, Pirkis JE, Slade TN, Johnston AK, Meadows GN \& Gunn JM. Service use for mental health problems: Findings from the 2007 national survey of mental health and wellbeing. Aust N Z J Psychiatry 2009; 43: 615-623.

14. Byers AL, Arean PA \& Yaffe K. Low use of mental health services among older americans with mood and anxiety disorders. Psychiatr Serv 2012; 63: 66-72.

15. Dixon LB, Holoshitz Y \& Nossel I. Treatment engagement of individuals experiencing mental illness: Review and update. World Psychiatry 2016; 15: 13-20.

16. Rees G, Ponczek E, Hassell J, Keeffe JE \& Lamoureux EL. Psychological outcomes following interventions for people with low vision: A systematic review. Expert Rev Ophthalmol 2014; 5: 385-403.

17. Rees G, Xie J, Chiang PP et al. A randomised controlled trial of a self-management programme for low vision implemented in low vision rehabilitation services. Patient Educ Couns 2015; 98: 174-181.

18. van der Aa HP, Margrain TH, van Rens GH, Heymans MW \& van Nispen RM. Psychosocial interventions to improve mental health in adults with vision impairment: Systematic review and meta-analysis. Ophthalmic Physiol Opt 2016; 36: 584-606.

19. van Nispen RM, Virgili G, Hoeben $M$ et al. Low vision rehabilitation for better quality of life in visually impaired adults. Cochrane Database Syst Rev 2020; 1: CD006543. 
Mental health and age-related macular degeneration

20. Tong A, Sainsbury P \& Craig J. Consolidated criteria for reporting qualitative research (coreq): A 32-item checklist for interviews and focus groups. Int J Qual Health Care 2007; 19: 349-357.

21. Pope C, Ziebland S \& Mays N. Qualitative research in health care. Analysing qualitative data. BMJ 2000; 320: 114-116.

22. Saunders B, Sim J, Kingstone T et al. Saturation in qualitative research: Exploring its conceptualization and operationalization. Quality \& Quantity 2018; 52: 1893-1907.

23. Michie S, van Stralen MM \& West R. The behaviour change wheel: A new method for characterising and designing behaviour change interventions. Implement Sci 2011; 6: 42.

24. Vaismoradi M, Turunen $\mathrm{H} \&$ Bondas T. Content analysis and thematic analysis: Implications for conducting a qualitative descriptive study. Nurs Health Sci 2013; 15 : 398-405.

25. Srivastava P \& Hopwood N. A practical iterative framework for qualitative data analysis. International Journal of Qualitative Methods 2009; 8: 76-84.

26. van der Aa HPA, Hoeben M, Rainey L, van Rens GHMB, Vreeken HL \& van Nispen RMA. Why visually impaired older adults often do not receive mental health services: The patient's perspective. Qual Life Res 2015; 24: 969-978.

27. Jones GC, Rovner BW, Crews JE \& Danielson ML. Effects of depressive symptoms on health behavior practices among older adults with vision loss. Rehabil Psychol 2009; 54: 164-172.

28. Pollard TL, Simpson JA, Lamoureux EL \& Keeffe JE. Barriers to accessing low vision services. Ophthalmic Physiol Opt 2003; 23: 321-327.

29. Gresset J \& Baumgarten M. Prevalence of visual impairment and utilization of rehabilitation services in the visually impaired elderly population of quebec. Optom Vis Sci 2002; 79: 416-423.

30. Hong T, Mitchell P, Burlutsky G, Gopinath B, Liew G \& Wang JJ. Visual impairment and depressive symptoms in an older australian cohort: Longitudinal findings from the blue mountains eye study. Br J Ophthalmol 2015; 99: 1017-1021.

31. Horowitz A \& Reinhardt JP. Adequacy of the mental health system in meeting the needs of adults who are visually impaired. J Vis Impair Blind 2006; 100: 871-874.

32. Dillon L, Tang D, Liew G et al. Facilitators and barriers to participation in mental wellbeing programmes by older australians with vision impairment: Community and stakeholder perspectives. Eye 2020; 34: 1287-1295.

33. Fenwick EK, Lamoureux EL, Keeffe JE, Mellor D \& Rees G. Detection and management of depression in patients with vision impairment. Optom Vis Sci 2009; 86: 948-954.

34. Lee E-KO \& Brennan M. 'I cannot see flowers but i can smell them': The relation of age and gender to self-reported coping strategies among older adults with visual impairment Qual Soc Work 2016; 1: 389-411.

35. Holloway EE, Sturrock BA, Lamoureux EL, Keeffe JE \& Rees G. Help seeking among vision-impaired adults referred to their gp for depressive symptoms: Patient characteristics and outcomes associated with referral uptake. Aust J Prim Health 2015; 21: 169-175.

36. Nyman SR, Dibb B, Victor CR \& Gosney MA. Emotional well-being and adjustment to vision loss in later life: A meta-synthesis of qualitative studies. Disabil Rehabil 2012; 34: 971-981.

37. King EA, Gilson SE, \& \& Peveler RC. Psychosocial needs of elderly visually impaired patients: Pilot study of patients' perspectives. Prim Care Ment Health 2006; 4: 185-197. 
Mental health and age-related macular degeneration

38. Bennion AE, Shaw RL \& Gibson JM. What do we know about the experience of age related macular degeneration? A systematic review and meta-synthesis of qualitative research. Soc Sci Med 2012; 75: 976-985.

39. Michie S, Richardson M, Johnston $\mathrm{M}$ et al. The behavior change technique taxonomy (v1) of 93 hierarchically clustered techniques: Building an international consensus for the reporting of behavior change interventions. Ann Behav Med 2013; 46: 81-95. 
Mental health and age-related macular degeneration

Figure 1. The impact of vision loss on mental health and mental wellbeing programmes, from the perspectives of people primarily with late age-related macular degeneration (AMD), based on the Capability, Opportunity, Motivation and Behaviour (COM-B) model (inner wheel) and intervention functions (outer wheel) of the behaviour change wheel. ${ }^{23}$ Personal factors, which may have influenced these perspectives, are also displayed. 